\title{
Efficient Swelling and Mercerization of Bagasse Fiber by Freeze-Thaw-Assisted Alkali Treatment
}

\section{OPEN ACCESS}

Edited by:

Jia-Long Wen,

Beijing Forestry University, China

Reviewed by:

Xin Zhou,

Nanjing Forestry University, China

Xiaolin Luo,

Fujian Agriculture and Forestry

University, China

*Correspondence:

Shuangquan Yao

yaoshuangquan@gxu.edu.cn

Specialty section:

This article was submitted to

Bioenergy and Biofuels,

a section of the journal

Frontiers in Energy Research

Received: 10 January 2022

Accepted: 24 January 2022

Published: 22 February 2022

Citation:

Cao L, Zhu J, Deng B, Zeng F, Wang S, Ma Y, Qin C and Yao S (2022) Efficient Swelling and Mercerization of Bagasse Fiber by Freeze-Thaw-Assisted

Alkali Treatment.

Front. Energy Res. 10:851543. doi: 10.3389/fenrg.2022.851543

\author{
Liming Cao, Jiatian Zhu, Baojuan Deng, Fanyan Zeng, Shanshan Wang, Yun Ma, \\ Chengrong Qin and Shuangquan Yao*
}

Guangxi Key Laboratory of Clean Pulp and Papermaking and Pollution Control, School of Light Industrial and Food Engineering, Guangxi University, Nanning, China

The mercerization of fiber is an important method for the high-value utilization of cellulose. In this study, the bagasse fiber was mercerized by freeze-thaw-assisted alkali treatment (FT/AT). The effects of freezing temperature, freezing time, alkali concentration, and thawing temperature on cellulose and hemicellulose removal were studied. The optimal freezing temperature was $-40^{\circ} \mathrm{C}$, freezing time was $8.0 \mathrm{~h}$, alkali concentration was $5.0 \%$, and thawing temperature was $30^{\circ} \mathrm{C}$. The highest removal rate of hemicellulose was 75.64\%. It was $5.80 \%$ higher than that of alkali treatment (AT). The alkaline degradation of cellulose was inhibited. The penetration of alkaline solution to fiber was promoted by the assistance of freeze-thaw pretreatment. The effective alkali concentration (5.0\%) of cellulose I completely transformed into cellulose II decreased by $66.67 \%$ compared with traditional alkaline mercerization (15.0\%). The high-efficiency mercerization of fiber was achieved by FT/AT. It provides theoretical support for promoting the high-value utilization of lignocellulosic biomass.

Keywords: alkali treatment, freeze-thaw, hemicellulose, cellulose, swelling, mercerization

\section{INTRODUCTION}

Currently, lignocellulosic biomass plays an important role in the energy, chemical, and material fields because of its zero carbon dioxide emissions, high content, and renewable properties (Luo et al., 2021; Zhu et al., 2020). Cellulose is the main component of the lignocellulosic biomass (Bian et al., 2019). In addition to pulp fibers, it is used to produce bioethanol and various functional materials, such as microcrystalline cellulose, medical cellulose, and high-absorbent cellulose materials (Alexakis et al., 2021; Li X. et al., 2021; Pang et al., 2015). The most widely used in the industry is cellulose II, although cellulose I occurs naturally (Yagura et al., 2020)' (Kita et al., 2020). Cellulose II is obtained by dissolution/regeneration (Reyes et al., 2020) or mercerization (Marzouki et al., 2019). Fibers are inflated using sodium hydroxide solution (Öztürk et al., 2006). The hemicellulose in the amorphous region is dissolved as alkali diffuses (Marzouki et al., 2019; Yu et al., 2017), and cellulose II is obtained. Smooth and round fibers are obtained by mercerization. The fiber kink index increases, and the content of fine components decreases (Noori et al., 2021). Mercerized fibers have good air permeability and chemical stability (Kumar et al., 2011; Oladele et al., 2019). They are widely used in the preparation of air filter paper, dictionary paper, and blotting paper. The color uniformity, fabric surface smoothness, and size stability of the cotton fabric is improved by printing. 


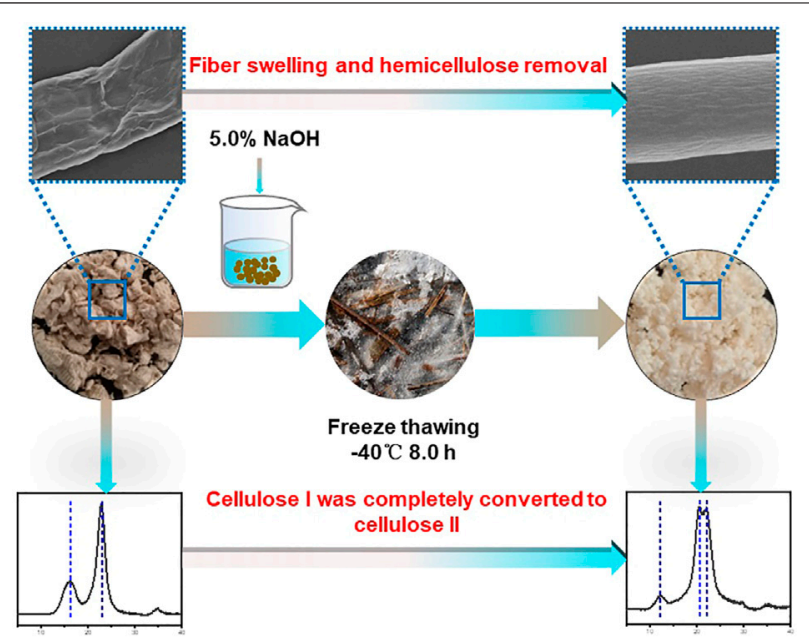

GRAPHICAL ABSTRACT |

Fibers are mercerized using traditional high alkali concentration treatments (15.00-18.00\%) (Albán Reyes et al., 2016). The crystalline form of cellulose changes at full swelling. Helena et al. (Halonen et al., 2013) investigated the effect of mercerization on the cellulose supramolecular structure and water retention value. The results showed that partial cellulose II was obtained using $11.00 \%$ sodium hydroxide. Liu et al. (Liu \& Hu, 2008) studied the effect of mercerization on the supramolecular structure of bamboo fibers. It was found that the crystalline form of cellulose changed when the sodium hydroxide concentration was greater than $12.00 \%$. The effects of alkali treatment temperature and time and alkali concentration on cellulose lattice conversion were studied (SaifulAzry et al., 2017). The results showed that cellulose I was completely converted to cellulose II in a $20.00 \%$ sodium hydroxide solution. The thermal stability of the mercerized fibers improved. However, a small amount of cellulose was dissolved during the alkaline degradation, and the cellulose yield decreased. This is a technical problem that needs to be overcome in fiber mercerization. Presently, the mercerization of bleached chemical pulp is employed for the high-value utilization of the traditional pulp fiber (Albán Reyes et al., 2016). However, the mercerization effect and the swelling of the fibers are inhibited by the presence of a small amount of hemicellulose in the pulp (Chen et al., 2020). The hemicellulose is efficiently separated using a new alkali treatment. David et al. (Ibarra et al., 2010) used xylanase and endoglucanase pretreatments-assisted alkali treatment. The removal rate of hemicellulose in the sulfate bleaching chemical pulp was $82.00 \%$. The effect of hemicellulose removal in sulfite pulp by mechanical grinding-assisted alkali treatment was studied by Li (Li et al., 2015). The pore volume and specific surface area of the pulp fibers are increased by mechanical grinding. The dissolution of hemicellulose is facilitated by alkali treatment, and the effective alkali concentration is significantly reduced. Additionally, freeze-thaw pretreatment has been employed to assist alkali treatment for the efficient separation of hemicellulose (Li J. et al., 2021). The results showed that the extraction rate of hemicellulose was $64.71 \%$. This means that the infiltration of alkali was enhanced by the freeze-thaw pretreatment.
Therefore, it is of great significance to study the mercerization of chemical pulp by freeze-thaw-assisted alkali treatment (FT/AT).

In this study, the fiber of bleached bagasse pulp was mercerized by FT/AT. The effects of freezing temperature, freezing time, alkali concentration, and thawing temperature on cellulose and hemicellulose removal were studied. The intrinsic viscosity, thermal stability, and water retention value of the fibers after the different treatments were analyzed. The morphology and physicochemical properties of the fibers were analyzed by scanning electron microscopy (SEM), specific surface area analysis (Brunauer-Emmett-Teller theory (BET)), Fouriertransform infrared spectroscopy (FTIR), X-ray diffraction (XRD), and fiber quality analysis. It provides theoretical support for the efficient mercerization of fibers.

\section{MATERIALS AND METHODS}

\section{Materials}

Bleached bagasse pulp was supplied by a local factory (Guangxi, China). The viscosity, brightness, and Kappa number of the pulp were $776 \mathrm{ml} \mathrm{g}^{-1}, 76 \% \mathrm{ISO}$, and 3.1, respectively. The details are listed in Table 1. The main chemical composition was analyzed (Ge et al., 2020). The cellulose and hemicellulose contents were 80.19 and $13.56 \%$, respectively. $90 \%$ of Sodium hydroxide solution was purchased from Sigma-Aldrich (United States). Other analytical chemicals were purchased from Aladdin Biotechnology Co., Ltd. (Shanghai, China).

\section{Swelling of Bagasse Fiber}

The bagasse fiber was swollen by FT/AT. The air-dried bagasse pulp $(10 \mathrm{~g})$ was thoroughly soaked in an alkali solution $(240 \mathrm{ml})$. The pulp was frozen in an ultra-low temperature quick-freezing machine (ILG500DFD; Bitzer, Sindelfingen, Germany). The solid-liquid ratio was 1: 24. The pulp was treated at different freezing temperatures, freezing times, and alkali concentrations. It was 
TABLE 1 | Chemical properties of bagasse fiber with different treatments.

\begin{tabular}{lccc} 
& Bagasse pulp & AT & FT/AT \\
\hline Yield (\%) & 100 & $78.35 \pm 2.13$ & $84.47 \pm 2.41$ \\
Cellulose (\%) & $80.19 \pm 0.87$ & $71.88 \pm 1.62$ & $76.48 \pm 1.34$ \\
Hemicellulose (\%) & $13.56 \pm 0.26$ & $4.09 \pm 0.17$ & $1.82 \pm 0.13$ \\
Viscosity $\left(\mathrm{ml} . \mathrm{g}^{-1}\right.$ ) & $776 \pm 2.53$ & $833 \pm 2.69$ & $845 \pm 2.78$ \\
Polymerization degree & $1,135 \pm 3.26$ & $1,229 \pm 3.74$ & $1,248 \pm 3.82$ \\
Fiber length $(\mathrm{mm})$ & $0.73 \pm 0.04$ & $0.59 \pm 0.01$ & $0.59 \pm 0.01$ \\
Fiber width $(\mu \mathrm{m})$ & $18.21 \pm 0.27$ & $16.96 \pm 0.17$ & $17.33 \pm 0.21$ \\
Fine fiber content $(\%)$ & $6.67 \pm 0.29$ & $4.43 \pm 0.16$ & $3.31 \pm 0.13$ \\
Form factor $(\%)$ & $89.55 \pm 1.32$ & $82.92 \pm 1.48$ & $82.41 \pm 1.28$ \\
Kink angle $\left({ }^{\circ}\right)$ & $51.63 \pm 0.73$ & $59.14 \pm 0.86$ & $61.90 \pm 0.79$ \\
Kink index $\left(\mathrm{mm}^{-1}\right)$ & $0.82 \pm 0.04$ & $1.57 \pm 0.02$ & $1.68 \pm 0.01$ \\
Specific surface area $\left(\mathrm{m}^{2} . \mathrm{g}^{-1}\right)$ & $0.54 \pm 0.03$ & $0.63 \pm 0.05$ & $1.04 \pm 0.02$ \\
Pore volume $\left(\times 10^{-3} \mathrm{~cm}^{-3} \mathrm{~g}^{-1}\right)$ & $2.80 \pm 0.05$ & $2.65 \pm 0.02$ & $2.00 \pm 0.03$ \\
Aperture $(\mathrm{nm})$ & $19.51 \pm 0.39$ & $12.50 \pm 0.25$ & $10.82 \pm 0.32$ \\
Water retention value $(\%)$ & $114 \pm 2.16$ & $149 \pm 3.37$ & $163 \pm 3.41$
\end{tabular}

completely thawed at different temperatures. Then, the treated pulp was obtained by vacuum extraction and filtration. The pulp was washed with pure water until after reaction. Then, it was air-dried and sealed. The swelling properties of the fiber was compared with those of traditional high-concentration AT (Halonen et al., 2013). $10 \mathrm{~g}$ of pulp was placed in $15.0 \%$ alkali at $50^{\circ} \mathrm{C}$ for $60 \mathrm{~min}$.

\section{Chemical Composition of the Pulp With Different Treatments}

The contents of cellulose and hemicellulose in pulp with different treatments were analyzed (Ge et al., 2020). The specific method and process were described by Cavali and co-authors (Cavali et al., 2020). The removal rates of cellulose and hemicellulose were calculated using Eqs 1, 2.

$$
\begin{aligned}
& \mathrm{R}_{\mathrm{H}}=\left(\mathrm{C}_{1}-\mathrm{C}_{2}\right) / \mathrm{C}_{2} * 100 \%, \\
& \mathrm{R}_{\mathrm{C}}=\left(\mathrm{C}_{3}-\mathrm{C}_{4}\right) / \mathrm{C}_{3} * 100 \%,
\end{aligned}
$$

Where $\mathrm{R}_{\mathrm{H}}$ is the removal rate of hemicellulose (\%), $\mathrm{C}_{1}$ is the hemicellulose content in the initial pulp $(\mathrm{g}), \mathrm{C}_{2}$ is the hemicellulose content in the treated pulp $(\mathrm{g}), \mathrm{R}_{\mathrm{C}}$ is the removal rate of cellulose (\%), $\mathrm{C}_{3}$ is the cellulose content in the initial pulp (g), and $\mathrm{C}_{4}$ is the cellulose content in the treated pulp (g).

\section{Physicochemical Properties of Fiber}

The surface morphology of bagasse fiber with different treatments was characterized by SEM (Quanta FEG 250, FEI, Hills-boro, Oregon, United States) (Yao et al., 2015). The pore volume, pore diameter, and specific surface area of the fiber was analyzed using a specific surface area and porosity analyzer (ASAP 2460; Micromeritics, United States). The length, width and fine fiber content of bagasse fiber were analyzed using a fiber quality analyzer (912, Lorentze \& Wettre, Sweden). The degree of hydration and swelling of the bagasse fiber was measured using the water retention value. The water retention value of the bagasse was calculated using Eq. 3.

$$
\mathrm{W}_{\mathrm{RV}}=\left(\mathrm{W}_{2-} \mathrm{W}_{1}\right) / \mathrm{W}_{1}{ }^{\star} 100 \%,
$$

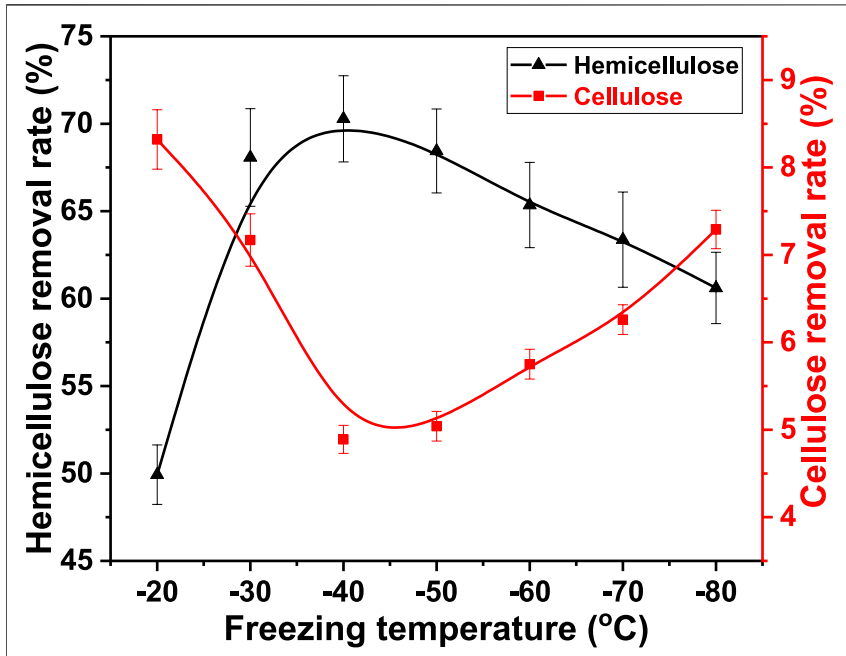

FIGURE 1 | Effect of freezing temperature on the removal rate of cellulose and hemicellulose from bagasse fiber in FT/AT.

Where $\mathrm{W}_{\mathrm{RV}}$ is the water retention value of the bagasse fiber (\%), $\mathrm{W}_{1}$ is the dry weight of the bagasse fiber $(\mathrm{g})$, and $\mathrm{W}_{2}$ is the weight of the wet bagasse fiber after centrifugation $(\mathrm{g})$.

The main functional groups of the different bagasse fiber was analyzed using FTIR (IRTracer-100, Shimadzu, Japan) (Yao et al., 2015). The effect of different treatments on the cellulose crystal shape was analyzed by XRD (Mini Flex 600, Rigaku, Tokyo, Japan) (Ge et al., 2020). The XRD patterns of the monochrome $\mathrm{Cu}-\mathrm{Ka}$ powders were used. The voltage and current were $40 \mathrm{kV}$ and $15 \mathrm{~mA}$, respectively. The scanning speed and scanning range were $0.131^{\circ} . S^{-1}$ and $5^{\circ}-50^{\circ}$, respectively. The thermal stability of the fiber was analyzed by thermogravimetric analysis (TGA) (STA 449F5, NETZSCH, Germany) (Tian et al., 2021).

\section{RESULTS AND DISCUSSION}

\section{Effect of Freezing Temperature on Fiber Swelling}

Wood fibers have strong thermal stability. The effective swelling of fiber is difficult to achieve at high temperatures. However, the softness of the object was enhanced by cryogenic freezing (Biglia et al., 2016). This indicates that fiber swelling can be promoted by freezing pretreatment. The key factors of freezing and thawing include freezing temperature, freezing time, and thawing temperature. Cellulose and hemicellulose were removed during the fiber swelling process. Therefore, the effect of freezing temperature on cellulose and hemicellulose removal was studied using FT/AT. It was $-20,-30,-40,-50,-60,-70$, and $-80^{\circ} \mathrm{C}$. The freezing time, alkali concentration, and thawing temperature was $6.0 \mathrm{~h}, 3.0 \%$, and $25^{\circ} \mathrm{C}$, respectively. The result is shown in Figure 1.

The removal rate of hemicellulose increased from 49.93 to $70.28 \%$ as the freezing temperature was increased from $-20^{\circ} \mathrm{C}$ to $-40^{\circ} \mathrm{C}$. However, it decreased as the freezing temperature decreased below 


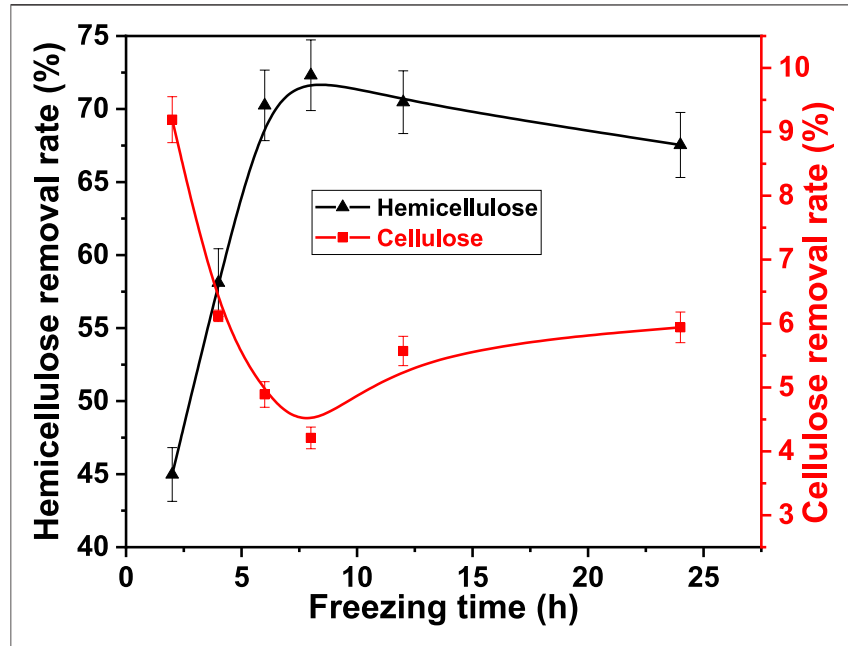

FIGURE 2 | Effect of freezing time on the removal rate of cellulose and hemicellulose from bagasse fiber in FT/AT.

$-40^{\circ} \mathrm{C}$. It was $60.61 \%$ at $-80^{\circ} \mathrm{C}$. The alkaline degradation of cellulose was inevitable during alkali infiltration (Liu et al., 2020). The removal rate of cellulose decreased with the decrease in freezing temperature when the freezing temperature was higher than $-40^{\circ} \mathrm{C}$. It decreased from 8.32 to $4.89 \%$. The degradation of cellulose was promoted when the freezing temperature was below $-40^{\circ} \mathrm{C}$. The removal rate of cellulose increased to $7.29 \%$ at $-80^{\circ} \mathrm{C}$. Fewer ice crystals were formed inside the fibers at the beginning of freezing. The alkaline degradation of cellulose was promoted by more alkaline solution in contact with cellulose. The formation and growth of the ice crystals in the fibers as the freezing temperature decreased (Zhang et al., 2021). The number of infiltration channels increased after thawing. The osmotic effect of alkaline solution was promoted with the increase in the number of physical channels. The removal of hemicellulose was facilitated. The removal of cellulose was inhibited. Uniform and fine ice crystals were formed at $-40^{\circ} \mathrm{C}$. The highest removal rate of hemicellulose and the lowest removal rate of cellulose were obtained. However, the ice crystals in the fiber increased as the freezing temperature decreased. Large ice crystals were formed by gobbling up fine ice crystals. Local damage to the fibers was exacerbated. The breakdown and dissolution of cellulose was intensified. Its removal rate increased as the freezing temperature decreased. The osmosis of alkaline solution was inhibited. The dissolution of hemicellulose was inhibited with the decrease in the overall swelling property of the fiber. Therefore, the optimal freezing temperature was $-40^{\circ} \mathrm{C}$ in FT/AT.

\section{Effect of Freezing Time on Fiber Swelling}

Freezing time is an important factor that affects food preservation during food refrigeration (Ben Haj Said et al., 2021). In fact, ice crystals grow irreversibly inside objects. Maintaining stable ice crystals is time sensitive. Therefore, the effect of freezing time on cellulose and hemicellulose removal was studied. It was 2.0, 4.0, $6.0,8.0,12.0$, and $24.0 \mathrm{~h}$. The freezing temperature was $-40^{\circ} \mathrm{C}$, alkali concentration was $3.0 \%$, and thawing temperature was $25^{\circ} \mathrm{C}$. The result is shown in Figure 2.

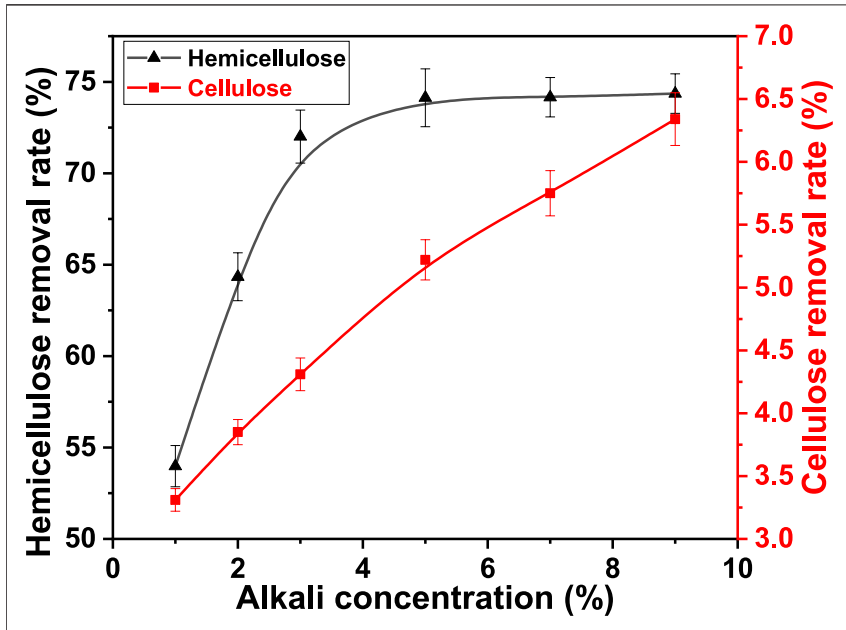

FIGURE 3 | Effect of alkali concentration on the removal rate of cellulose and hemicellulose from bagasse fiber in FT/AT.

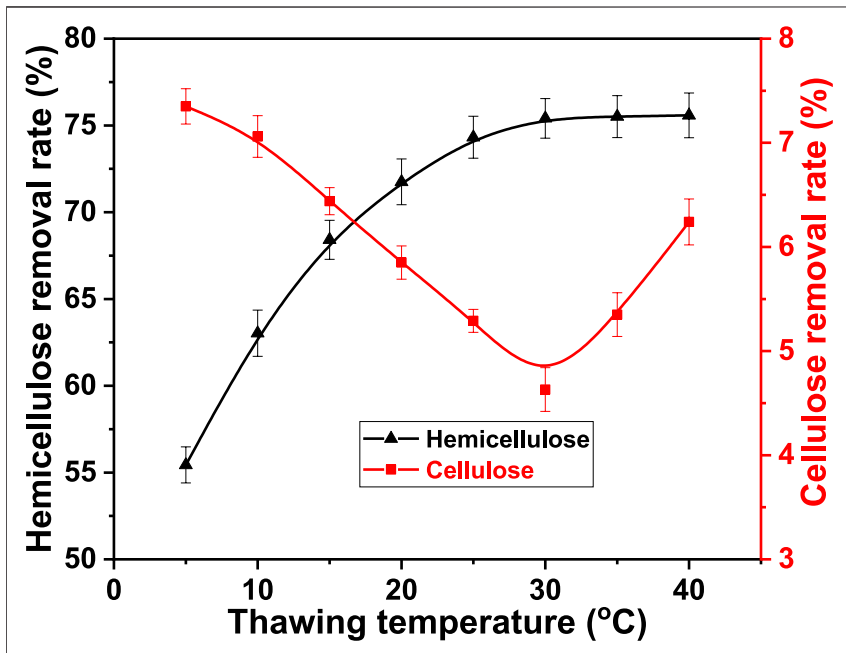

FIGURE 4 | Effect of thawing temperature on the removal rate of cellulose and hemicellulose from bagasse fiber in FT/AT.

The removal rate of hemicellulose increased with freezing time. It increased from $44.98 \%$ at $2.0 \mathrm{~h}$ to $72.31 \%$ at $8.0 \mathrm{~h}$. However, it decreased with freezing time when the freezing time was greater than $8.0 \mathrm{~h}$. It decreased to $67.54 \%$ at $24.0 \mathrm{~h}$. The removal rate of cellulose decreased from 9.19 to $4.21 \%$ when the freezing time was between 2.0 and $8.0 \mathrm{~h}$. The dissolution and degradation of cellulose were promoted under a relatively long freezing time. The removal rate of cellulose increased to $5.94 \%$ at $24.0 \mathrm{~h}$. It was attributed to the change in the number and size of ice crystals in the fiber with freezing time. The number of fine ice crystals increased with freezing time at the beginning of freezing (Gong et al., 2020). The number of physical channels for the penetration of liquid medicine increased accordingly. Therefore, the dissolution of hemicellulose was promoted. The alkaline degradation of cellulose was suppressed. The fine ice crystals were evenly distributed inside 
the fiber at $8.0 \mathrm{~h}$. Large ice crystals were formed by swallowing small ice crystals as the freezing time continued to increase. The damage caused by freezing to the fiber structure changed from slight-overall to significant-local. The breaking and dissolution of cellulose was promoted, the swelling of the fiber were reduced. The dissolution of hemicellulose was suppressed. Therefore, the optimal freezing time was $8.0 \mathrm{~h}$.

\section{Effect of Alkali Concentration on Fiber Swelling}

The swelling of the fiber in water was limited. However, the fiber crystallization area was permeated by acid, alkali, and salt. The swelling of the fiber was improved. The alkali concentration is an important parameter in AT. The removal of hemicellulose and alkaline degradation of cellulose are promoted. Therefore, the effect of alkali concentration on cellulose and hemicellulose removal was studied. It was $1.0,2.0,3.0,5.0,7.0$, and $9.0 \%$. The freezing temperature was $-40^{\circ} \mathrm{C}$, freezing time was $6.0 \mathrm{~h}$, and thawing temperature was $25^{\circ} \mathrm{C}$. The result is shown in Figure 3 .

It was observed that the alkali concentration significantly affected the removal of hemicellulose when the alkali concentration was less than $5.0 \%$. It increased from 53.98 to $74.13 \%$. Additionally, the effect of high alkali concentration on the removal of hemicellulose was limited. The removal rate of hemicellulose was $74.36 \%$ at an alkali concentration of $9.0 \%$. This was due to the increase in porosity indicated by the fiber after freezing. The penetration of alkali was enhanced. The effective contact between hemicellulose and alkali was strengthened. The removal rate of hemicellulose increased with the concentration of alkali. The result showed that cellulose was degraded under alkaline conditions (Zaccaron et al., 2020). The alkaline degradation of cellulose increased with the increase in alkali concentration. Therefore, the removal rate of cellulose increased linearly. It rapidly increased from 3.31 to $6.34 \%$. The optimal alkali concentration was $5.0 \%$ in FT/AT. More efficient mercerization was obtained at relatively low alkali concentrations.

\section{Effect of Thawing Temperature on Fiber Swelling}

Alkali treatment and thawing were carried out simultaneously. The alkali treatment time was compressed to obtain a better fiber swelling effect. Thawing and alkali penetration were simultaneously carried out. The alkaline degradation of cellulose was inhibited while realizing effective contact between hemicellulose and alkali. Therefore, the effect of thawing on cellulose and hemicellulose removal was studied by adjusting the thawing temperature. The temperature was $5,10,15,20,25,30,35$, and $40^{\circ} \mathrm{C}$. The freezing temperature was $-40^{\circ} \mathrm{C}$, freezing time was $8.0 \mathrm{~h}$, and alkali concentration was 5.0\%. The result is shown in Figure 4.

The removal rate of hemicellulose rapidly increased with the thawing temperature and then remained stable. It increased from 55.44 to $75.41 \%$ when the thawing temperature was between 5 and $30^{\circ} \mathrm{C}$. The thawing time increased as the temperature decreased. Further, the fluctuation of the temperature at the beginning of thawing directly caused the rapid formation of large ice crystals inside the fiber (Kumar et al., 2019). The destructiveness of the fiber structure was gradually enhanced. Severe local damage was formed. The infiltration effect of alkali solution was reduced in large channels formed by melting of large ice crystals. Its accessibility to hemicellulose was poor. More alkali was consumed from the alkaline degradation of cellulose. Therefore, the removal of hemicellulose was inhibited at low thawing temperatures. Conversely, the removal of cellulose was promoted. The growth of ice crystals inside the fiber was suppressed as the thawing temperature increased. The channels were quickly occupied by the alkali after the small ice crystals melted. The effective contact with the hemicellulose was strengthened. The removal rate of cellulose gradually decreased while the removal rate of hemicellulose gradually increased. It was reduced from 7.35 to $4.63 \%$ at $30^{\circ} \mathrm{C}$. The removal rate of hemicellulose remained stable as the thawing temperature increased due to most of the hemicellulose was removed. It was $75.58 \%$ at $40^{\circ} \mathrm{C}$. However, the alkaline degradation of cellulose was enhanced at relatively high temperatures (Knill \& Kennedy, 2003). Therefore, the removal rate of cellulose decreased as the thawing temperature increased to $>30^{\circ} \mathrm{C}$. The rate increased to $6.24 \%$ at $40^{\circ} \mathrm{C}$. The optimal thawing temperature was $30^{\circ} \mathrm{C}$.

The optimal condition of FT/AT was freezing temperature $-40^{\circ} \mathrm{C}$, freezing time $8.0 \mathrm{~h}$, alkali concentration $5.0 \%$, and thawing temperature $30^{\circ} \mathrm{C}$. The highest removal rate of hemicellulose was $75.64 \%$. It was $5.80 \%$ higher than that of AT treatment. The lowest removal rate of cellulose was $4.63 \%$. It was $5.73 \%$ lower than that of AT treatment. In addition, the effective alkali concentration (5.0\%) was reduced by $66.67 \%$ compared to AT (15.0\%). The energy consumption of freeze-thaw pretreatment was effectively compensated by the significant reduction of alkali consumption. Therefore, FT/AT is an efficient method for fiber swelling.

\section{Properties of Bagasse Fiber With Different Treatments}

The yield of bagasse fiber changed with the swelling and removal of hemicellulose. Table 1 shows the pulp fiber yield was $78.35 \%$ with AT. It was $84.47 \%$ after FT/AT. This was attributed to the different degrees of the dissolution of the main components during swelling. The penetration of alkali was promoted by freeze-thaw pretreatment (Li J. et al., 2021). The hemicellulose in the pulp was efficiently removed, and the alkaline degradation of cellulose was inhibited. The content of cellulose decreased from 80.19 to $76.48 \%$. The content of hemicellulose was significantly reduced from 13.56 to $1.82 \%$. Therefore, cellulose - rich bagasse fiber was obtained by FT/AT. The viscosity and degree of polymerization of fiber was affected. Table 1 show that the viscosity of the fiber increased from $776 \mathrm{ml} \mathrm{g}^{-1}$ to $833 \mathrm{ml} \mathrm{g}^{-1}$. This was due to the large amount of hemicellulose dissolved during AT. Additionally, the fiber with FT/AT had greater viscosity $\left(845 \mathrm{ml} \mathrm{g}^{-1}\right)$ than those treated with AT. Further, their degree of polymerization increased from 1,229 to 1,248. This was attributed to the structure of cellulose was protected while the hemicellulose was efficiently removed during FT/AT.

In fact, the morphology of the fiber is affected as the major components change. The fiber length, fiber width, and fine fiber 

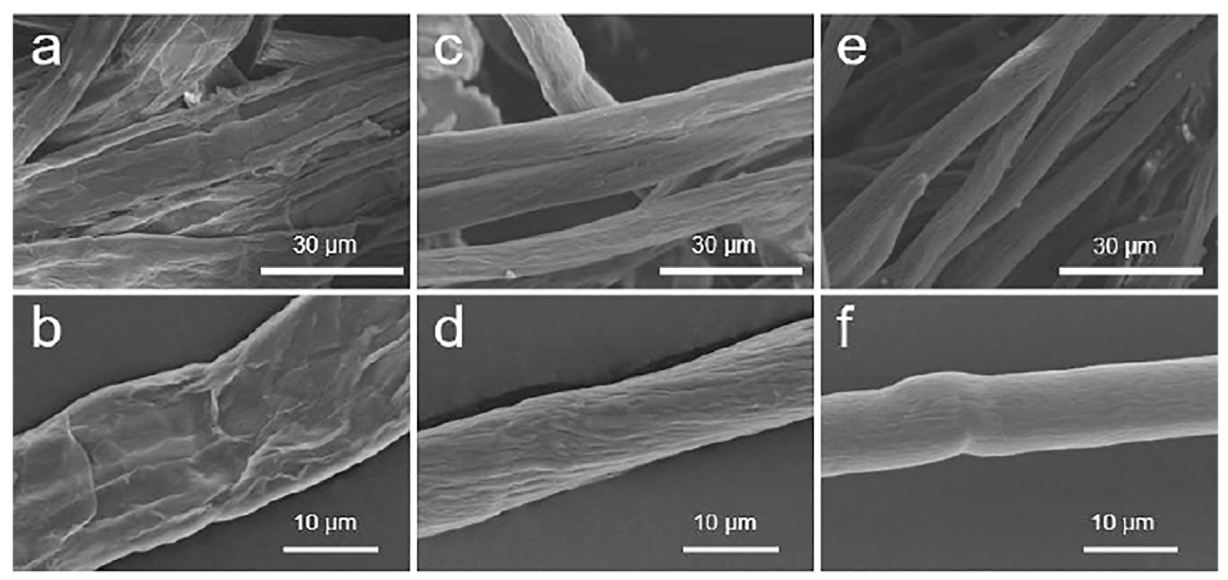

FIGURE 5 | SEM of bagasse fiber with different treatments (bleached bagasse pulp; AT; FT/AT.).

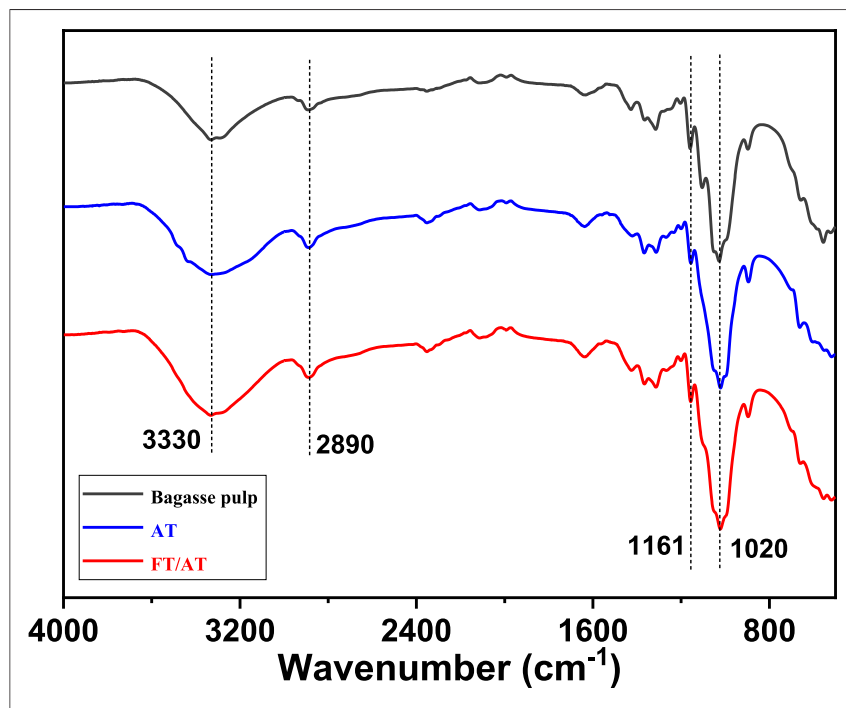

FIGURE 6 | FTIR of bagasse fiber with different treatments.

content were reduced by AT. Fiber length decreased from 0.73 to $0.59 \mathrm{~mm}$. Different alkali treatments had the same effect on the fiber length. However, there were differences in the fiber width. The fiber width after FT/AT treatment is larger than that after AT treatment. The fine fiber content decreased from 6.67 to $3.31 \%$. It was reduced by $1.13 \%$ compared to that of AT. The results showed that FT/AT had a higher swelling performance than AT. The effect of fiber mercerization action is reflected not only in the swelling performance but also in the kink index of the fiber (Suizu et al., 2009). The fiber form factor, kink angle, and kink index are important indices of fiber distortion. The fiber form factor is the ratio of the projected length of the fiber to the real length. The larger the value of the form factor, the straighter the fiber. The fiber form factors were reduced by 6.63 and $7.14 \%$ by AT and FT/AT, respectively. The kink angle increased from $51.63^{\circ}$ to $59.14^{\circ}$ and $61.90^{\circ}$, respectively. The kink index increased by $0.75 \mathrm{~mm}^{-1}$ and $0.86 \mathrm{~mm}^{-1}$, respectively. This indicates that the fiber had a relatively high kink index using FT/AT. The degree of

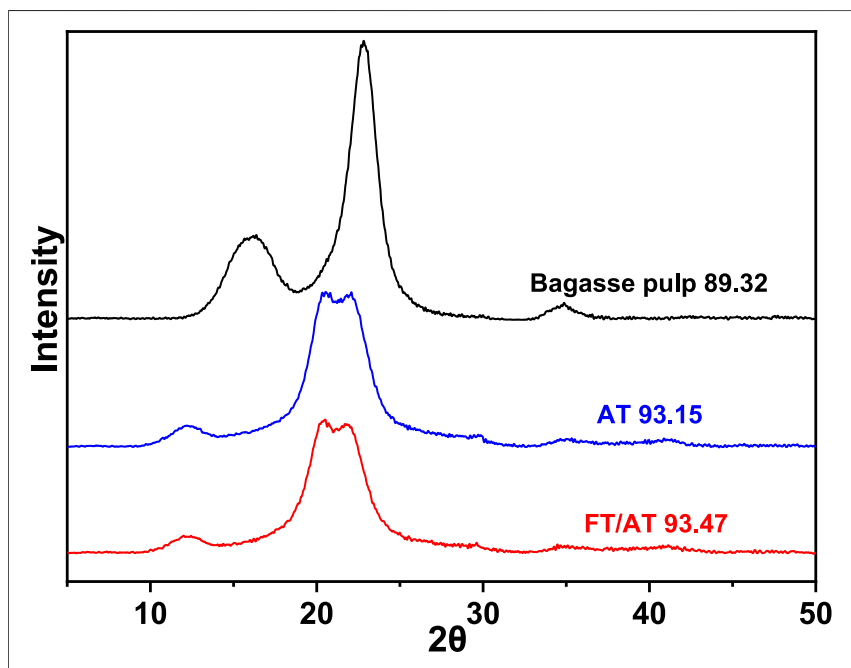

FIGURE 7 | XRD of bagasse fiber with different treatments.

hydration and swelling of the fiber was reflected by the water retention value. This is directly related to the specific surface area and porosity of the fiber (Arnoul-Jarriault et al., 2016). The water retention value of the bleached bagasse pulp fiber was $114 \%$, as shown in Table 1. It increased to $149 \%$ with AT. It significantly increased to $163 \%$ by FT/AT. This was attributed to the relatively high specific surface area of the fibers treated with FT/AT (1.04). Moreover, the fiber had a relatively high porosity owing to the few physical channels remaining after the fine ice crystals were melted during freezing and thawing. The water absorption and swelling performance of the fibers improved. More bound water was retained inside the fibers.

\section{Morphology and Physicochemical Properties of Bagasse Fiber With Different Treatments}

First, the surface of bagasse fiber was relatively rough (Figure 5). This was attributed to an amount of hemicellulose in the fiber and more 

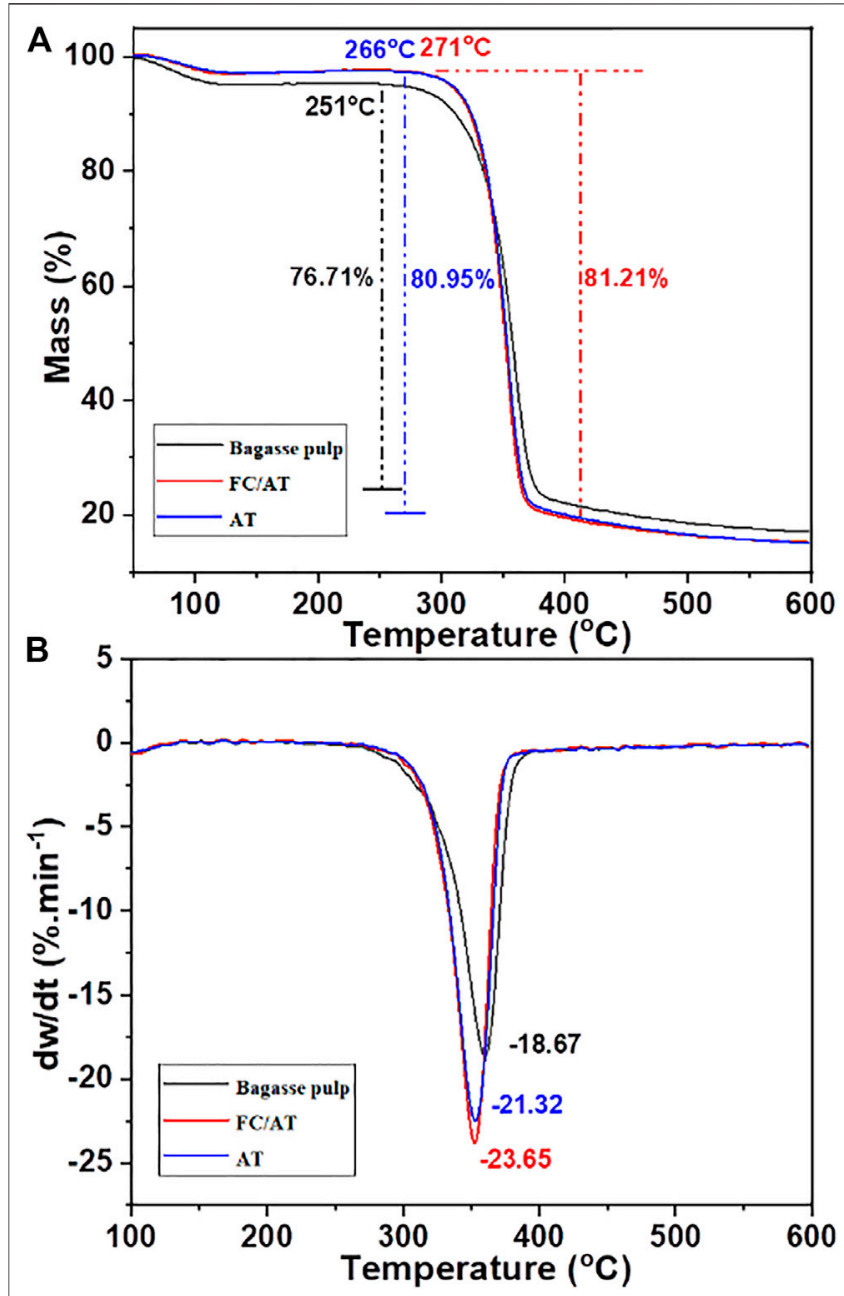

FIGURE 8 | TGA (A) and DTG (B) of bagasse fiber with different treatments.

fiber fines on the surface. The higher alkali concentration was used in AT to achieve good mercerization. Fine fibers and a large amount of hemicellulose were removed. However, the alkaline degradation of cellulose was promoted at high alkali concentration. This resulted in the presence of wrinkles on the fiber surface. Smooth, round fibers were obtained with FT/AT. This was attributed to the infiltration of alkali was promoted by FT/AT. Hemicellulose and fiber fines were efficiently removed. Further, the alkaline degradation of cellulose was inhibited at low alkali concentrations.

The changes in the fiber components before and after different treatments are shown in Figure 6. The characteristic peak at $3,300 \mathrm{~cm}^{-1}$ was attributed to the $\mathrm{O}-\mathrm{H}$ stretching vibration of carbohydrate (Yao et al., 2017). The intensities of the characteristic peaks were reduced with different treatments. This was attributed to the breaking of intermolecular and intramolecular hydrogen bonds. More importantly, a large amount of hemicellulose was removed. The absorption peak at $2,890 \mathrm{~cm}^{-1}$ was attributed to the stretching vibration of $\mathrm{C}-\mathrm{H}$ on saturated carbon. They are mainly derived from cellulose and hemicellulose. Additionally, the absorption peak intensity of $\mathrm{C}-\mathrm{O}$ stretching attributed to hemicellulose at $1,020 \mathrm{~cm}^{-1}$ decreased (Liu et al., 2021). This showed that the $\mathrm{C}-\mathrm{O}$ bond in hemicellulose was broken. A large amount of hemicellulose was removed. However, the absorption peaks at $1,161 \mathrm{~cm}^{-1}$ varied in the different treatments. This was attributed to the asymmetric stretching vibration of $\mathrm{C}-\mathrm{O}-\mathrm{C}$ in cellulose (Hosakun et al., 2017). Their strengths were the same in bagasse fiber and FT/AT-treated fiber. This indicates that the structure of the cellulose was protected by FT/AT. The alkaline degradation of cellulose was inhibited, while hemicellulose was efficiently removed. This was consistent with the results of the single-factor analysis.

The goal of mercerization is to change the crystal shape of cellulose. The XRD patterns of the pulp fibers are shown in Figure 7. The crystal peaks of the bleached bagasse pulp were observed at $16.5^{\circ}$ and $22.5^{\circ}$. They belong to cellulose I (Sèbe et al., 2012). The crystallization peak at $16.5^{\circ}$ completely disappeared after AT and FT/AT, and a new crystallization peak was observed at $12^{\circ}$. Additionally, the crystallization peak at $22.5^{\circ}$ moved to $20^{\circ}$ and $21^{\circ}$. These were the characteristic peaks of cellulose II(Nomura et al., 2020). That mercerization effects were obtained using different treatments. Complete mercerization was achieved at $15.0 \%$ alkali concentration with AT. The effect of different alkali concentration on cellulose crystal shape was studied by FT/AT. The lowest alkali concentration at which the crystalline form of cellulose is completely changed was $5.0 \%$ during FT/AT. The minimum alkali concentration of cellulose crystal by complete transformation was reduced by $66.67 \%$ compared with AT. This means that the efficient mercerization of the fibers was achieved by FT/AT, and relatively high fiber crystallinity was obtained (93.47). This was due to the cellulose structure was protected under low alkali concentrations.

In addition, mercerized fibers have relatively high thermal stability (Rashid et al., 2016). Therefore, the thermal decomposition behavior and thermal stability of the different fiber were analyzed. The TGA and derivative thermogravimetry (DTG) profiles of the fiber are shown in Figure 8.

Figure 8A shows that the initial pyrolysis temperature of the bagasse fiber was $251^{\circ} \mathrm{C}$. It was raised to 266 and $271^{\circ} \mathrm{C}$ after mercerization. This was attributed to the removal of hemicellulose and the change of cellulose crystal shape by different mercerization. Cellulose II exhibited better thermal stability than cellulose I. Additionally, the initial pyrolysis temperatures of these two types of mercerization were different. This was attributed to the removal of more hemicellulose by FT/AT. The maximum mass loss of the bagasse fiber was $76.71 \%$. It increased to 80.95 and $81.21 \%$ after mercerization. The alkaline degradation of cellulose was inhibited at low alkali concentrations. Figure $\mathbf{8 B}$ shows the maximum weight loss rate of the fibers under different treatment conditions. The maximum weight loss rate of the bleached bagasse fiber was $18.67 \% \cdot \mathrm{min}^{-1}$. It increased by $3.65 \% \cdot \mathrm{min}^{-1}$ and $4.98 \% \cdot \mathrm{min}^{-1}$ by mercerization. This was attributed to the removal of a large amount of hemicellulose and the improvement of cellulose purity. The thermal decomposition of cellulose was enhanced (Lin et al., 2019). Therefore, the maximum weight loss rate of the cellulose increased. The results showed that the thermal stability of 
cellulose was higher after FT/AT. This was attributed to a significant reduction in alkali concentration. The overall structure of cellulose was protected, while the crystalline form of cellulose was completely transformed. Further, the efficient mercerization effects were obtained. This provides a new method for the mercerization of fibers.

\section{CONCLUSION}

A new efficient mercerization for fiber has been discovered. The bleached bagasse pulp fiber was swelled by FT/AT. The bagasse hemicellulose was efficiently removed. The alkaline degradation of cellulose was inhibited at low alkali concentrations. The results showed that mercerized fibers with excellent properties were obtained. Cellulose I was completely converted into cellulose II at $5.0 \%$ alkali concentration. The minimum alkali concentration of cellulose crystal by complete transformation was reduced by $66.67 \%$ compared with AT. It provides theoretical support for the high-value utilization of cellulose.

\section{REFERENCES}

Albán Reyes, D. C., Skoglund, N., Svedberg, A., Eliasson, B., and Sundman, O. (2016). The Influence of Different Parameters on the Mercerisation of Cellulose for Viscose Production. Cellulose 23 (2), 1061-1072. doi:10.1007/s10570-0160879-0

Alexakis, A. E., Engström, J., Stamm, A., Riazanova, A. V., Brett, C. J., Roth, S. V., et al. (2021). Modification of Cellulose Through Physisorption of Cationic BioBased Nanolatexes - Comparing Emulsion Polymerization and RAFTMediated Polymerization-Induced Self-Assembly. Green. Chem. 23 (5), 2113-2122. doi:10.1039/d0gc04266h

Arnoul-Jarriault, B., Passas, R., Lachenal, D., and Chirat, C. (2016). Characterization of Dissolving Pulp by Fibre Swelling in Dilute Cupriethylenediamine (CUEN) Solution in a MorFi Analyser. HOLZFORSCHUNG 70 (7), 611-617. doi:10.1515/hf-2015-0167

Ben Haj Said, L., Bellagha, S., and Allaf, K. (2021). Instant Controlled Pressure Drop (DIC) Assisted Dehydrofreezing for Improving Freezing/thawing Efficiency and Apple Fruit Texture. Food Measure 15 (1), 577-584. doi:10. 1007/s11694-020-00668-x

Bian, H., Luo, J., Wang, R., Zhou, X., Ni, S., Shi, R., et al. (2019). Recyclable and Reusable Maleic Acid for Efficient Production of Cellulose Nanofibrils with Stable Performance. ACS Sustain. Chem. Eng. 7 (24), 20022-20031. doi:10. 1021/acssuschemeng.9b05766

Biglia, A., Comba, L., Fabrizio, E., Gay, P., and Aimonino, D. R. (2016). Case Studies in Food Freezing at Very Low Temperature. Energ. Proced. 101, 305-312. doi:10.1016/j.egypro.2016.11.039

Cavali, M., Soccol, C. R., Tavares, D., Zevallos Torres, L. A., Oliveira de Andrade Tanobe, V., Zandoná Filho, A., et al. (2020). Effect of Sequential Acid-Alkaline Treatment on Physical and Chemical Characteristics of Lignin and Cellulose from Pine (Pinus spp.) Residual Sawdust. Bioresour. Tech. 316, 123884. doi:10. 1016/j.biortech.2020.123884

Chen, Q., Wang, X., Huang, H., Cao, S., Chen, L., Huang, L., et al. (2020). Turkey Red Oil - An Effective Alkaline Extraction Booster for Enhanced Hemicelluloses Separation from Bamboo Kraft Pulp and Improved Fock Reactivity of Resultant Dissolving Pulp. Ind. Crops Prod. 145, 112127. doi:10.1016/j.indcrop.2020.112127

Ge, J., Wu, Y., Han, Y., Qin, C., Nie, S., Liu, S., et al. (2020). Effect of Hydrothermal Pretreatment on the Demineralization and Thermal Degradation Behavior of Eucalyptus. Bioresour. Tech. 307, 123246. doi:10.1016/j.biortech.2020.123246

\section{DATA AVAILABILITY STATEMENT}

The original contributions presented in the study are included in the article/Supplementary Material, further inquiries can be directed to the corresponding author.

\section{AUTHOR CONTRIBUTIONS}

LC: Conceptualization and Writing - review and editing; JZ and BD: Investigation and Writing - original draft; CQ: Funding acquisition and Resources; FZ and SW: Validation; YM: Formal analysis; SY: Project administration and Supervision.

\section{FUNDING}

This project was sponsored by the National Natural Science Foundation of China (22078075). This project was supported by the Natural Science Foundation of Guangxi Province (2020GXNSFBA297164).

Gong, Y., Xu, S., He, T., Dong, R., Ren, T., Wang, X., et al. (2020). Effect of QuickFreezing Temperature on Starch Retrogradation and Ice Crystals Properties of Steamed Oat Roll. J. Cereal Sci. 96, 103109. doi:10.1016/j.jcs.2020.103109

Halonen, H., Larsson, P. T., and Iversen, T. (2013). Mercerized Cellulose Biocomposites: A Study of Influence of Mercerization on Cellulose Supramolecular Structure, Water Retention Value and Tensile Properties. Cellulose 20 (1), 57-65. doi:10.1007/s10570-012-9801-6

Hosakun, Y., Halász, K., Horváth, M., Csóka, L., and Djoković, V. (2017). ATRFTIR Study of the Interaction of $\mathrm{CO} 2$ with Bacterial Cellulose-Based Membranes. Chem. Eng. J. 324, 83-92. doi:10.1016/j.cej.2017.05.029

Ibarra, D., Köpcke, V., Larsson, P. T., Jääskeläinen, A.-S., and Ek, M. (2010). Combination of Alkaline and Enzymatic Treatments as a Process for Upgrading Sisal Paper-Grade Pulp to Dissolving-Grade Pulp. Bioresour. Tech. 101 (19), 7416-7423. doi:10.1016/j.biortech.2010.04.050

Kita, Y., Kusumi, R., Kimura, T., Kitaoka, M., Nishiyama, Y., and Wada, M. (2020). Surface Structural Analysis of Selectively 13C-Labeled Cellulose II by Solid-State NMR Spectroscopy. Cellulose 27 (4), 1899-1907. doi:10.1007/s10570-019-02896-X

Knill, C. J., and Kennedy, J. F. (2003). Degradation of Cellulose Under Alkaline Conditions. Carbohydr. Polym. 51 (3), 281-300. doi:10.1016/s0144-8617(02) 00183-2

Kumar, P. K., Bhunia, K., Tang, J., Rasco, B. A., Takhar, P. S., and Sablani, S. S. (2019). State/phase Transitions Induced by Ice Recrystallization and its Influence on the Mechanical Properties of Potatoes (Solanum tuberosum L.) Var. Russet Brown. J. Food Eng. 251, 45-56. doi:10.1016/j.jfoodeng. 2019.02.002

Kumar, V., Kushwaha, P. K., and Kumar, R. (2011). Impedance-spectroscopy Analysis of Oriented and Mercerized Bamboo Fiber-Reinforced Epoxy Composite. J. Mater. Sci. 46 (10), 3445-3451. doi:10.1007/s10853-011-5249-6

Li, J., Liu, Y., Duan, C., Zhang, H., and Ni, Y. (2015). Mechanical Pretreatment Improving Hemicelluloses Removal from Cellulosic Fibers During Cold Caustic Extraction. Bioresour. Tech. 192, 501-506. doi:10.1016/j.biortech.2015.06.011

Li, J., Liu, Z., Feng, C., Liu, X., Qin, F., Liang, C., et al. (2021a). Green, Efficient Extraction of Bamboo Hemicellulose Using Freeze-Thaw Assisted Alkali Treatment. Bioresour. Tech. 333, 125107. doi:10.1016/j. biortech.2021.125107

Li, X., Du, Y., and Meng, Q. (2021b). Flexible ball-milled Bi0.4 Sb1.6 Te3/methyl Cellulose Thermoelectric Films Fabricated by Screen-Printing Method. Funct. Mater. Lett. 14 (06), 2151034. doi:10.1142/s1793604721510346

Lin, X., Kong, L., Cai, H., Zhang, Q., Bi, D., and Yi, W. (2019). Effects of Alkali and Alkaline Earth Metals on the Co-pyrolysis of Cellulose and High Density 
Polyethylene Using TGA and Py-GC/MS. Fuel Process. Tech. 191, 71-78. doi:10. 1016/j.fuproc.2019.03.015

Liu, P., Pang, B., Dechert, S., Zhang, X. C., Andreas, L. B., Fischer, S., et al. (2020). Structure Selectivity of Alkaline Periodate Oxidation on Lignocellulose for Facile Isolation of Cellulose Nanocrystals. Angew. Chem. Int. Ed. 59 (8), 3218-3225. doi:10.1002/anie.201912053

Liu, X., Renard, C. M. G. C., Bureau, S., and Le Bourvellec, C. (2021). Revisiting the Contribution of ATR-FTIR Spectroscopy to Characterize Plant Cell wall Polysaccharides. Carbohydr. Polym. 262, 117935. doi:10. 1016/j.carbpol.2021.117935

Liu, Y., and Hu, H. (2008). X-ray Diffraction Study of Bamboo Fibers Treated with NaOH. Fibers Polym. 9 (6), 735-739. doi:10.1007/s12221-008-0115-0

Luo, Y., Li, Y., Cao, L., Zhu, J., Deng, B., Hou, Y., et al. (2021). High Efficiency and Clean Separation of eucalyptus Components by Glycolic Acid Pretreatment. Bioresour. Tech. 341, 125757. doi:10.1016/j.biortech.2021. 125757

Marzouki, R., Brahmia, A., Bondock, S., Keshk, S. M. A. S., Zid, M. F., Al-Sehemi, A. G., et al. (2019). Mercerization Effect on Structure and Electrical Properties of Cellulose: Development of a Novel Fast Na-Ionic Conductor. Carbohydr. Polym. 221, 29-36. doi:10.1016/j.carbpol.2019.05.083

Nomura, S., Kugo, Y., and Erata, T. (2020). 13C NMR and XRD Studies on the Enhancement of Cellulose II Crystallinity with Low Concentration $\mathrm{NaOH}$ Post-treatments. Cellulose 27 (7), 3553-3563. doi:10.1007/s10570-02003036-6

Noori, A., Lu, Y., Saffari, P., Liu, J., and Ke, J. (2021). The Effect of Mercerization on Thermal and Mechanical Properties of Bamboo Fibers as a Biocomposite Material: A Review. Construction Building Mater. 279, 122519. doi:10.1016/j.conbuildmat.2021. 122519

Oladele, I. O., Ibrahim, I. O., Akinwekomi, A. D., and Talabi, S. I. (2019). Effect of Mercerization on the Mechanical and Thermal Response of Hybrid Bagasse Fiber/CaCO3 Reinforced Polypropylene Composites. Polym. Test. 76, 192-198. doi:10.1016/j.polymertesting.2019.03.021

Öztürk, H. B., Okubayashi, S., and Bechtold, T. (2006). Splitting Tendency of Cellulosic Fibers. Part 2: Effects of Fiber Swelling in Alkali Solutions. Cellulose 13 (4), 403-409. doi:10.1007/s10570-006-9054-3

Pang, Q., Tang, J., Huang, H., Liang, X., Hart, C., Tam, K. C., et al. (2015). A Nitrogen and Sulfur Dual-Doped Carbon Derived from Polyrhodanine@ Cellulose for Advanced Lithium-Sulfur Batteries. Adv. Mater. 27 (39), 6021-6028. doi:10.1002/adma.201502467

Rashid, B., Leman, Z., Jawaid, M., Ghazali, M. J., and Ishak, M. R. (2016). Physicochemical and Thermal Properties of Lignocellulosic Fiber from Sugar palm Fibers: Effect of Treatment. Cellulose 23 (5), 2905-2916. doi:10. 1007/s10570-016-1005-z

Reyes, G., Lundahl, M. J., Alejandro-Martín, S., Arteaga-Pérez, L. E., Oviedo, C., King, A. W. T., et al. (2020). Coaxial Spinning of All-Cellulose Systems for Enhanced Toughness: Filaments of Oxidized Nanofibrils Sheathed in Cellulose II Regenerated from a Protic Ionic Liquid. Biomacromolecules 21 (2), 878-891. doi:10.1021/acs.biomac.9b01559

SaifulAzry, S. O. A., Chuah, T. G., Paridah, M. T., Aung, M. M., and Edi, S. Z. (2017). Effects of Polymorph Transformation via Mercerisation on Microcrystalline Cellulose Fibres and Isolation of Nanocrystalline Cellulose Fibres. Pertanika J. Sci. Tech. 25 (4), 1275-1290.
Sèbe, G., Ham-Pichavant, F., Ibarboure, E., Koffi, A. L. C., and Tingaut, P. (2012). Supramolecular Structure Characterization of Cellulose II Nanowhiskers Produced by Acid Hydrolysis of Cellulose I Substrates. Biomacromolecules 13 (2), 570-578. doi:10.1021/bm201777j

Suizu, N., Uno, T., Goda, K., and Ohgi, J. (2009). Tensile and Impact Properties of Fully Green Composites Reinforced with Mercerized Ramie Fibers. J. Mater. Sci. 44 (10), 2477-2482. doi:10.1007/s10853-009-3317-y

Tian, Z., Chee, T.-S., Zhang, X., Lei, L., and Xiao, C. (2021). Novel Bismuth-Based Electrospinning Materials for Highly Efficient Capture of Radioiodine. Chem. Eng. J. 412, 128687. doi:10.1016/j.cej.2021.128687

Yagura, T., Ikegami, W., Kamitakahara, H., and Takano, T. (2020). Synthesis of an Enantiomer of Cellulose via Cationic Ring-Opening Polymerization. Cellulose 27 (17), 9755-9766. doi:10.1007/s10570-020-03512-z

Yao, S., Nie, S., Yuan, Y., Wang, S., and Qin, C. (2015). Efficient Extraction of Bagasse Hemicelluloses and Characterization of Solid Remainder. Bioresour. Tech. 185, 21-27. doi:10.1016/j.biortech.2015.02.052

Yao, S., Nie, S., Zhu, H., Wang, S., Song, X., and Qin, C. (2017). Extraction of Hemicellulose by Hot Water to Reduce Adsorbable Organic Halogen Formation in Chlorine Dioxide Bleaching of Bagasse Pulp. Ind. Crops Prod. 96, 178-185. doi:10.1016/j.indcrop.2016.11.046

Yu, H., Guo, J., Chen, Y., Fu, G., Li, B., Guo, X., et al. (2017). Efficient Utilization of Hemicellulose and Cellulose in Alkali Liquor-Pretreated Corncob for Bioethanol Production at High Solid Loading by Spathaspora Passalidarum U1-58. Bioresour. Tech. 232, 168-175. doi:10.1016/j.biortech.2017.01.077

Zaccaron, S., Henniges, U., Potthast, A., and Rosenau, T. (2020). How Alkaline Solvents in Viscosity Measurements Affect Data for Oxidatively Damaged Celluloses. Cuoxam and Cadoxen. Carbohydr. Polym. 240, 116251. doi:10.1016/j.carbpol.2020.116251

Zhang, T., Wang, L., Wang, Z., Li, J., and Wang, J. (2021). Single Ice Crystal Growth with Controlled Orientation During Directional Freezing. J. Phys. Chem. B 125 (3), 970-979. doi:10.1021/acs.jpcb.0c11028

Zhu, H., Ma, Q., Sheng, J., and Yang, R. (2020). Freeze-thaw Repetition as an Auxiliary Method to Promote Efficient Separation of Hemicellulose from poplar. Green. Chem. 22 (3), 942-949. doi:10.1039/c9gc03792f

Conflict of Interest: The authors declare that the research was conducted in the absence of any commercial or financial relationships that could be construed as a potential conflict of interest.

Publisher's Note: All claims expressed in this article are solely those of the authors and do not necessarily represent those of their affiliated organizations, or those of the publisher, the editors and the reviewers. Any product that may be evaluated in this article, or claim that may be made by its manufacturer, is not guaranteed or endorsed by the publisher.

Copyright $(2022$ Cao, Zhu, Deng, Zeng, Wang, Ma, Qin and Yao. This is an openaccess article distributed under the terms of the Creative Commons Attribution License (CC BY). The use, distribution or reproduction in other forums is permitted, provided the original author(s) and the copyright owner(s) are credited and that the original publication in this journal is cited, in accordance with accepted academic practice. No use, distribution or reproduction is permitted which does not comply with these terms. 